"Futuröck: primera radio profesional por internet en Argentina"

Emiliano Rimoldi

Question/Cuestión, Vol 2 N66, Agosto 2020.

ISSN: 1669-6581

https://perio.unlp.edu.ar/ojs/index.php/question/

IICom - FPyCS - UNLP

\title{
“FUTURÖCK: PRIMERA RADIO PROFESIONAL POR INTERNET EN ARGENTINA"
}

\section{"FUTURÖCK: FIRST PROFESSIONAL INTERNET RADIO IN ARGENTINA"}

\section{Emiliano Rimoldi}

Licenciado en Comunicación Social - Doctorando en Comunicación (FPyCS/UNLP) - Becario de la CICpBA emirimoldi@gmail.com

https://orcid.org/0000-0003-0858-4509 Instituto de Investigaciones en Comunicación - IICom

\section{Resumen}

En esta entrevista con Federico Vázquez, director de Futuröck, analizamos la experiencia de la primera radio por internet de Argentina y las perspectivas sobre el futuro de la radio. 


\title{
Palabras clave
}

Radio, Internet, Telecomunicaciones

\begin{abstract}
In this interview with Federico Vázquez, Futuröck's director, we analize the experience of the first internet radio of Argentina and their perspective of de radio's future.
\end{abstract}

\section{Keywords}

Radio, Internet, Telecommunications

\section{Enlace:}

https://go.ivoox.com/rf/55803961 